Tesis. Año 14, 13(16), 2020, 97-110

\title{
La literatura en la perspectiva de la ecocrítica
}

\author{
Edwin Camasca \\ edwincamasca@gmail.com
}

\section{Resumen}

El artículo aborda los fundamentos de la ecocrítica y su vínculo con el estudio de la literatura. El texto tiene por propósito explicar los principios, propuestas y objetivos de la ecocrítica, así como su contribución en la formación de una conciencia crítica acerca de los problemas relacionados con el medio ambiente. Desde la mirada de la ecocrítica, las obras literarias ilustran la existencia de graves problemas medioambientales, evidencian la acción del hombre en el proceso de la destrucción de la naturaleza, revelan la actitud utilitaria que caracteriza a la explotación de los recursos naturales y pone de relieve la falta de un verdadero compromiso del ser humano con su hábitat. Mediante una revisión de la literatura española e hispanoamericana, el artículo analiza las características de la relación hombre-naturaleza en el marco de la ecocrítica. En esa perspectiva, dicha relación resulta fundamental en la poesía de los pueblos nativos, tal como se expresa en la voz de los poetas mapuches.

Palabras clave: ecocrítica, ecoliteratura, literatura y medio ambiente, ética del escritor, poesía mapuche.

\section{Abstract}

The paper addresses the fundamentals of ecocriticism and its link to the study of literature. The purpose of the text is to explain the principles, porposals and objectives of ecocriticism, as well as its contribution to the formation of a critical awareness about environmental issues. From the perspective of ecocriticism, literary Works illustrate the existence of serious environmental problems, demonstrate the action of man in the process of the destruction of nature, reveal the utilitarian attitude that characterizes the exploitation of natural resources and highlights the lack of a true commitment of the human being with his hábitat. Through a review of Spanish and Latin Americcan literature, the paper analyzes the characteristics of the man-nature relationship within the framework of ecocriticism. In that perspective, this relationship is fundamental in the poetry of the native peoples, as expressed in the voice of the Mapuche poets.

Key words: ecocriticism, ecoliterature, literature and environment, writer's ethics, Mapuche poetry. 


\section{La literatura en la perspectiva de la ecocrítica}

\section{Un acercamiento a la ecocrítica}

La crisis que vive actualmente el medio ambiente, con las graves implicancias que acarrea para la existencia del ser humano ha producido en los últimos años una seria preocupación por el estado en que se encuentra la naturaleza. Ello, a su vez, ha generado una mayor conciencia sobre los problemas medioambientales, así como la urgencia de tomar medidas que limiten de alguna manera el impacto de la acción del hombre sobre la naturaleza y la biodiversidad. En ese contexto, la creación artística y la literatura no han estado al margen de los problemas y conflictos que afectan al medio ambiente, pues dada su especial sensibilidad para representar las acciones humanas y las implicancias que ellas conllevan, han logrado plasmar las contradicciones que enfrenta el mundo, así como suscitar una reflexión sobre la crisis que vive el planeta. En ese sentido, el estudio de las obras literarias también pone en evidencia las diferentes relaciones y actitudes que el ser humano ha tenido con la naturaleza a través de la historia de la civilización humana.

Desde esta nueva perspectiva, la ecocrítica incide en poner de relieve las percepciones que los textos literarios brindan de estas relaciones o actitudes con el fin de hacer ver si el hombre ha vivido en armonía con su entorno natural desarrollando una valoración de las plantas, los animales, los ríos, los lagos, etc.; o si, por el contrario, el ser humano ha actuado explotando los recursos naturales y creando una relación conflictiva con el medio ambiente. La ecocrítica llama la atención sobre la existencia de una valoración y respeto del hombre hacia el medio ambiente o acerca de su carencia en el tratamiento de la naturaleza que lo lleve a repensar sus acciones. En esa línea, abordar la literatura desde la ecocrítica brinda una identificación con el medio ambiente, valora su importancia para el ser humano, sensibiliza sobre la conservación de los recursos naturales, incentiva una toma de conciencia sobre los daños a los ecosistemas y contribuye a mentalizar acerca de la aplicación de medidas que urge poner en práctica para 
enfrentar la crisis medioambiental y proteger a la naturaleza en sus variadas formas.

Para hacer ver cómo ha cambiado el enfoque de la naturaleza, la ecocrítica se ha planteado visibilizar la forma cómo se realiza la representación de la naturaleza, analizar dicha representación, discutir y problematizar los valores y la ideología que se halla detrás de dicha representación. Por ello, la literatura ha empezado a ser revisitada y estudiada a partir de este giro que penetra en los problemas actuales derivados del tratamiento y explotación con que el hombre interactúa con la naturaleza. Este giro permite estudiar explicar y analizar los nuevos problemas que enfrenta la humanidad y le permite al hombre acercarse a ellos tratando de encontrar respuestas y nuevas formas de reflexión y de acción que lo lleven a resituarse ante la naturaleza.

En ese horizonte, la reproducción de los conflictos a través de la literatura nos interpela sobre la tarea impostergable y urgente de atender la realidad actual y las múltiples amenazas que afectan al planeta, a la naturaleza y a la humanidad, todo lo cual es producto de la propia actuación, irresponsabilidad y soberbia del ser humano. Si bien la idea de que la literatura y los estudios sobre las obras literarias deben tener un valor útil, esta condición no anula la calidad estética de la creación literaria, ni el hecho de ser un arte de creación; por el contrario, opera en la necesidad de que los códigos estéticos apunten a cuestiones de mayor trascendencia y valor.

\section{Definición de ecocrítica}

La ecocrítica es una nueva tendencia de crítica literaria que surge hacia los años 90 del siglo pasado en el oeste norteamericano; estudia la literatura tomando en consideración de qué manera se representa la relación del ser humano con el medio ambiente en los textos literarios lo que revelan estos acerca de la conducta del hombre sobre la naturaleza. Sobre la necesidad del estudio de la ecocrítica, Cheryll Glotfelty sostiene:

La ecocrítica es el estudio de las relaciones entre la literatura y el medio ambiente, $y$ plantea que, al igual que el género, la clase social, la raza o los procesos postcoloniales se han convertido en categorías de análisis literario, también ha de serlo el lugar. En este campo, forzosamente interdisciplinar, centenares de críticos trabajan hoy fieles a la premisa ecológica de que todo está interconectado, y confiados en la certeza de que es imposible (...) desvincular la calidad estética de una obra de su contexto socia-económico y político, pero también del ecológico. (Cit. de Flys et al., 2010, p. 16)

El objetivo primordial de la ecocrítica se centra en la relación del ser humano con la tierra, por lo que se propone acercar al ser humano hacia ella y 
enseñarle cómo mejorar su relación con el medio ambiente. En su evolución, la ecocrítica ha seguido un derrotero que la ha posicionado como un estudio que ha reflexionado sobre el vínculo del hombre con la naturaleza y ha replanteado el acercamiento del ser humano a ella. Centrada, en un principio, en "la búsqueda de imágenes de la naturaleza en la literatura canónica como los arquetipos del Edén o Arcadia" o en "la ausencia significativa del mundo natural en una obra", la ecocrítica se propuso luego "el intento de rescatar la tradición marginada de una literatura ecológica, escrita desde la perspectiva de la naturaleza"; finalmente, se orienta a un plano de reflexión al llegar a "una fase teórica preocupada por las construcciones literarias del ser humano en su relación con el entorno natural" (Flys et al., 2010, p. 16).

A lo largo de la historia de la literatura, las relaciones entre las obras literarias y la ecología siempre han existido y han presentado diversas formas. Se puede observar que la representación del lugar dentro de las obras literarias es un tema frecuente en la literatura y que ha primado, igualmente, una representación de los vínculos entre el paisaje y los seres humanos y no humanos en los textos literarios. Sin embargo, más allá de esta comprobación, "la ecocrítica procura fijarse en la materialidad física y científica del lugar, pasando de los abstracto, pasivo o simbólico a lo tangible, todo ello con una clara concienciación ecológica" (Flys et al, 2010, p. 17).

En los estudios ecocríticos se plantea que el modo cómo se desarrolla esta relación del hombre con el medio ambiente es determinante para la construcción de una identidad local, geográfica, histórica o personal, y que dicha identidad explicaría las actitudes existentes hacia la naturaleza y cómo las personas perciben el medio ambiente. Igualmente, dicha identidad explicaría nuestras actitudes ante la crisis ecológica que vivimos el día de hoy.

\section{Fundamentos filosóficos de la ecocrítica}

Los estudios teóricos sobre la ecocrítica han tomado como punto de partida las reflexiones provenientes de la filosofía, que describen las actitudes de los seres humanos frente al medio ambiente y las implicancias que dichas conductas conllevan para la existencia de la naturaleza. Entre las disciplinas humanísticas, la filosofía nos ofrece una línea de reflexión y acercamiento a las cuestiones que plantean la crisis medioambiental y las derivaciones que se generan de la acción del hombre:

En filosofía, varias ramas como la ética medioambiental, la ecología profunda, el ecofeminismo y la ecología social han surgido en un esfuerzo por entender y criticar las causas raíces de la degradación medioambiental, y por formular una visión alternativa de la existencia que proporcione una fundación ética y conceptual que permita establecer relaciones justas con la tierra. (Flys et al., 2010, p. 58) 
En el campo de la filosofía, se distinguen dos posiciones: la perspectiva predominante y la filosofía de la ecología profunda, entre las cuales existen radicales diferencias que contrastan dos formas de concebir la relación el hombre con la naturaleza. La primera tendencia se halla ligada al antropocentrismo, vertiente en la que el hombre asume una acción sin límites sobre la naturaleza, mientras que la segunda representa al biocentrismo, cuya forma de asumir el vínculo del ser humano con la tierra opera en términos de respeto y valoración para con el medio ambiente.

De acuerdo con el siguiente análisis de estas dos concepciones, podemos contraponer los fundamentos de la perspectiva predominante y la filosofía de la ecología profunda a través de una serie de criterios. En principio, la primera cree en el dominio del ser humano sobre la naturaleza, con las implicancias que ello conlleva para la existencia de esta; mientras que la filosofía de la ecología cree en la armonía del ser humano con la naturaleza como un principio de gran necesidad y valor. Por otro lado, para la primera tendencia, el ambiente natural es asumido como un conjunto de recursos naturales que pueden ser libremente explotados, en tanto que la segunda considera a toda la naturaleza como un conjunto en el cual cada elemento tiene un valor intrínseco, lo que permite entender su verdadera existencia y dinámica interior.

Entre ambas corrientes, igualmente, se confrontan planteamientos que están referidos a la manera de conceptuar la satisfacción en relación con el aprovechamiento de la naturaleza. Así, en la perspectiva predominante, se busca crecer económicamente para satisfacer los deseos de los seres humanos sin otro objetivo que alcanzar ese estado confortable; la posición de la filosofía de la ecología profunda, en cambio, consiste en la satisfacción plena y elegante que yace en vivir de una manera respetuosa con el medio ambiente. En esa misma dirección, se agrega el hecho de que la tendencia predominante es conocida por abogar por la vasta existencia de los recursos naturales, lo que desde la mirada de la filosofía de la ecología profunda constituye una grave equivocación, ya que la realidad evidencia la limitada existencia de dichos recursos. Cabe resaltar que los planteamientos que han predominado para justificar el aprovechamiento de la naturaleza, y que han beneficiado al capitalismo y a las empresas transnacionales, ha merecido en los últimos años una serie de críticas y severos cuestionamientos.

En el proceso de explotación de los recursos naturales, el pensamiento que ha tenido mayor dominancia considera que las soluciones y el progreso deben estar basados en la tecnología avanzada. Desde esta perspectiva, el avance tecnológico, industrial y científico se convierte en el soporte decisivo del progreso de los países y sin él no sería posible su bienestar ni su desarrollo. No obstante, en los planteamientos de la filosofía de la ecología profunda, dicho avance es un factor determinante del daño que se produce a la naturaleza. Por ello, esta 
dirección sostiene que el uso de la tecnología no debe dañar a la naturaleza ni al ser humano, tampoco debe dominar al ser humano y a la naturaleza en general.

En otro plano, se puede observar que satisfacer y promover los intereses del consumidor, con las implicancias comerciales y la creación de una permanente demanda, sirve de norte al pensamiento predominante. En contraparte, vivir una vida saludable y satisfecha, reciclando y evitando el derroche y desperdicio, actúa como motor de la filosofía de la ecología profunda. La actuación y la política administrativa de los Estados inciden en las cuestiones medioambientales. En esa línea, está del lado de la corriente predominante el tipo de gobierno centralista, cuyas políticas repercuten a nivel comunitario y nacional en su favor. Para la segunda tendencia, la descentralización y el respeto a las sociedades y comunidades minoritarias son fundamentales. De esta manera, situándonos en los alcances de esta segunda corriente, el Estado y los gobiernos tienen una responsabilidad en el deterioro medioambiental al haber propiciado con su estructura organizativa y administrativa el incremento de la destrucción de la naturaleza.

En suma, desde el enfoque de la filosofía, se plantea un contraste entre dos formas de concebir la relación de hombre con la naturaleza: una inclinación utilitarista y económica del medio ambiente, plasmada en una actitud materialista y comercial, que se reafirma en la poca o nula consideración de la naturaleza con su consecuente deterioro o destrucción; y una actitud contraria, que se sostiene en el respeto, la valoración y el aprecio de la naturaleza en el marco de una vida armoniosa entre el hombre y el medio ambiente.

\section{La ética del escritor en la perspectiva de la ecocrítica}

La ecocrítica exige una toma de posición que compromete a los creadores en la tarea de crear conciencia y fomentar una reflexión crítica que contribuyan a la defensa del medioambiente y su conservación. En un contexto como el actual, el llamado a actuar en salvaguarda de la tierra se traduce en un compromiso ineludible que convoca a los cultores del arte, la literatura y de toda forma de creación. Es decir, la ecocrítica instituye también una dimensión ética correlativa al espíritu creativo que demanda una respuesta asertiva de los artistas, escritores, pensadores, etc.

Situándonos en el campo de la ecocrítica, la ética del escritor impone un deber, un concepto sobre el sentido de la vida, una convicción, una forma de actuar y un modo de asumir la relación con el hábitat que nos cobija. La ética del escritor no es un concepto abstracto, sino, más bien, actúa como un principio, una convicción, una posición que lo sitúa en un aquí y un ahora. La ética gobierna la acción del escritor y encamina el acto creador en consonancia con 
elevados principios, valores y actitudes que representan objetivos mayores del ser humano.

E1 ecologismo apela a la función social de la literatura y confía en el rol transformador que tiene sobre la sociedad el arte literario. En ese propósito, el escritor comprometido adquiere una tarea vital en nuestros días que contribuye, mediante la creación literaria, a una sensibilización y a una toma de conciencia sobre las acciones humanas y los problemas derivados de la explotación de la naturaleza que tienen un impacto ecológico irreversible.

En la perspectiva ecologista, lo estético no se deja de lado, ya que los textos literarios mantienen sus características estéticas y creativas, conservan sus elementos constitutivos y sus propiedades formales, y continúan siendo una producción textual. Ello, no obstante, adquiere una mayor dimensión y alcance cuando el escritor se adhiere a las demandas de los tiempos actuales que reclaman una creación más ligada y comprometida con los problemas que afectan al hombre y a su entorno vital. El arte y la literatura no necesariamente se desvinculan de un sentido cívico, de una actitud responsable y auténticamente verdadera, porque cifran también las expectativas del hombre y se inspiran en los valores trascendentes del ser humano.

\section{Una mirada ecocrítica a la literatura española}

En un estudio dedicado a analizar la función de la naturaleza y del paisaje en la literatura española, Julia Barella destaca la mirada que proporciona la ecocrítica en el estudio de los textos españoles: "La ecocrítica incorpora un enfoque enriquecedor a la hora de revisar algunas de nuestras obras literarias, si atendemos a la relación del escritor, de sus personajes y/o sus metáforas con el medio ambiente (...) tiene también un interesante ingrediente de concienciación y formación social que, sin duda, debemos valorar" (2010, p. 219).

Desde la perspectiva de la ecocrítica, es posible conocer cómo se ha construido el paisaje en los textos literarios, apreciar sus características estéticas, valorar su historia y poner de relieve el significado que adquiere para la cultura española. Esta mirada contribuye, igualmente, en la tarea de recuperar el puesto del hombre en el lugar que habita y a tomar conciencia sobre la tarea urgente de protegerlo.

Tomando como referencia la literatura del renacimiento, el romanticismo, el realismo y la generación del 98, podemos apreciar que existen diferentes imágenes de la naturaleza en los escritores españoles. Así, desde una exaltación del paisaje, asistimos a una presentación de la naturaleza que se sobrepone al ser humano, así como a un cuestionamiento del impacto de la modernidad y la tecnología sobre la vida rural; a ello se añade el hecho de que la literatura 
española se centra en el paisaje como una forma de encontrarse y de ir hacia su propia raíz ancestral.

La literatura del renacimiento español valoró la naturaleza, lo que se expresó a través de la contemplación y la admiración que los escritores sintieron por ella. Los tópicos literarios como el locus amoenus y el beatus ille, procedentes del caudal de la literatura clásica, revelan la valoración del paisaje en la literatura española. Un escenario bello y encantador donde prima la armonía y los seres de la naturaleza es el marco en que se desarrollan las conocidas Églogas de Garcilaso de la Vega; similar escenario se observa en la poesía mística del Siglo de Oro, tanto en los versos de Cantico espiritual de San Juan de la Cruz que describen una naturaleza llena de esplendor y simbolismo, y en la conocida oda $A$ la vida retirada de Fray Luis de León, que es una celebración espiritual de la vida en el campo en oposición a lo mundanidad de la ciudad. En esa misma línea, la narrativa pastoril celebra las bondades de la naturaleza y su carácter ideal, tal como se puede apreciar en Los siete libros de Diana de Jorge de Montemayor y La Galatea de Miguel de Cervantes.

La literatura del romanticismo y del realismo español plantea otra perspectiva de la naturaleza, que es diferente del carácter ornamental y que, más bien, asume un rol protagónico frente al hombre. Así, la naturaleza reacciona ante las amenazas y la invasión del hombre sobre su espacio y los seres que lo habitan. Las Leyendas de Bécquer ofrecen esta imagen de la naturaleza que se defiende ante la acción del hombre que quiere ir más allá de sus fronteras; en la novela Los pazos de Ulloa de Emilia Prado Bazán, la naturaleza se impone sobre los hombres por no querer respetar sus leyes. La crítica y el cuestionamiento a los avances tecnológicos y al impacto que producen en la zona rural y en la vida de la naturaleza a fines del siglo XIX se desarrollan en obras como Adiós Cordera de Leopoldo Alas.

En los escritores de la generación del 98, se expresa un sentimiento de admiración y valoración del paisaje castellano, lo que se vincula con un proyecto de afirmación del sentimiento nacional en España. Los miembros de esta brillante generación comparten el anhelo de "construir una idea de nación ligada a una idea de paisaje, un paisaje con carácter identitario, con capacidad para definir al país y sus habitantes, y también capaz de identificarse con la lengua castellana y su literatura" (Barella, 2010, p. 229).

Algunos títulos que revelan la importancia del paisaje en el espíritu del 98 son obras muy conocidas en la literatura española: Granada la bella de Ángel Ganivet, La ruta de don Quijote de Azorín, Camino de perfección de Pío Baroja, Por tierras de Portugal y España de Miguel de Unamuno y Campos de Castilla de Antonio Machado. Esta vocación por la descripción del paisaje afirma lo que se denominó en su momento "lo esencial castellano", que impulsó el proyecto generacional del 98. En momentos en que urgía definir el destino de España y 
existía una preocupación por el ser español, el paisaje alcanzó la dimensión de signo de la identidad española.

La atención por el paisaje como núcleo vital de la producción literaria del 98 pone de manifiesto la búsqueda de un sentimiento de patriotismo que encuentra en la geografía un elemento vital. De esta manera, la naturaleza y el paisaje actúan como un factor clave para conocer la historia y la realidad pasada, y se convirtieron en un signo de la identidad española.

\section{La narrativa hispanoamericana a la luz de la ecocrítica}

Con diferentes matices, el tema de la naturaleza ha sido uno de los principales tópicos que se han desarrollado en las letras del continente. En los inicios de la literatura de la independencia hispanoamericana, Andrés Bello en La agricultura de la zona tórrida describe los elementos vitales del suelo americano en tono admirativo y ve en la naturaleza un signo de la construcción de la identidad del continente. El romanticismo argentino aborda asuntos vinculados con el paisaje, la pampa y la vitalidad de la tierra en obras como La cautiva de Esteban Echeverría, Amalia de José Mármol y Facundo de Domingo Faustino Sarmiento.

El enfrentamiento del hombre con la naturaleza caracteriza al tema de la tierra en el ciclo de la novela regionalista. En novelas como La vorágine de José Eustacio Rivera y Doña Bárbara de Rómulo Gallegos, la pugna del hombre con la naturaleza se produce en términos de su explotación y aprovechamiento basados en un supuesto deber moral que le permite al hombre actuar libremente sobre ella y someterla bajo su dominio. Paredes y McLean explican que en esta lucha el ser humano se arroga el derecho moral de "transformar y destruir la fuente del subdesarrollo, el primitivismo y la maldad, que toma forma de bosques, animales, ríos, selvas, montañas, lagos" (Cit. de Marrero, 2010, p. 194).

La explotación de la Amazonía en la novela de Rivera pone de relieve el espíritu antropocéntrico de la acción humana, así como la mirada utilitarista que existió durante los años de la explotación del caucho con el consecuente daño al medio ambiente y la puesta en práctica acciones de extrema violencia en contra de las poblaciones nativas. En la novela de Gallegos, igualmente, prevalece la mirada del antropocentrismo, representada en Santos Luzardo, personaje que encarna un ideal de progreso que, en el fondo, está en contradicción con la existencia de la propia naturaleza. William Flores sostiene que el afán tecnocéntrico del hombre se puede apreciar en la mecanización del llano venezolano "y en la explotación de la naturaleza sin la provisión alguna al mundo natural o a las necesidades que seres vivos no-humanos tienen", primando "el bienestar y la comodidad del ser humano sin interesar el efecto que esta comodidad tenga 
en otros seres vivientes y, consecuentemente, en el propio ser humano" (2015, p. 68).

En la novela La serpiente de oro de Ciro Alegría, que gira en torno a la vida de los balseros del río Marañón en su diario enfrentamiento con el gran río de la selva amazónica, se aborda de modo similar el proyecto de una empresa encabezada por un ingeniero limeño que tiene como objetivo el aprovechamiento de los minerales de la selva. El personaje se instala en la floresta amazónica para conocer la posible área de explotación y explora las cuencas cercanas donde se puede encontrar oro. En el proyecto del ingeniero se representa la expansión económica del capital y el desarrollo industrial de la modernidad que en su avance sobre la selva amazónica solo busca utilidad y el interés crematístico.

Una perspectiva diferente proyecta la narrativa hispanoamericana sobre la relación del hombre con el medio ambiente en un corpus de novelas que asumen dicho vínculo en términos de denuncia e interpelación. En ese propósito, Paredes y McLean afirman que los escritores latinoamericanos han sabido "elevar sus voces en contra de la destrucción sistemática de los recursos naturales" (Cit. de Marrero, 2010, p. 194). Situadas en el ámbito del ecologismo, las novelas se adhieren a la valoración del medio ambiente y expresan su malestar por el deterioro que experimenta como consecuencia de la acción del hombre.

Entre las novelas que asumen esta perspectiva, podemos citar Dolor de patria de José Rutilio Quesada, en la que se admira la flora y la fauna por lo que significan por sí mismas, además de cuestionar la utilización de la naturaleza y la violencia contra la población nativa. Por otro lado, una profunda sensibilidad ecológica anima la temática de las novelas La mujer habitada, Sofía de los presagios y Waslala de Gioconda Belli, La loca de Gandoca de Anacristina Rossi y Mundo del fin del mundo de Luis Sepúlveda, en las que también se desarrolla una adhesión a los valores de la naturaleza.

Paredes y McLean consideran que la literatura ecologista del continente está definida por cinco criterios: expresar una denuncia constante, situarse en el horizonte de la cultura aborigen, redescubrir los mitos populares y aborígenes, incorporar hechos verídicos y el cuestionamiento de la historia oficial. La inclinación de la literatura ecologista por lo indígena se explica por el especial significado de las raíces históricas y culturales de los pueblos del continente y por el papel decisivo de lo nativo en la constitución del sentimiento americano.

\section{La poesía mapuche y la defensa de la tierra y de la cosmovisión ancestral}

La defensa de la tierra no ha estado exenta de un reclamo que liga la actitud contestataria con una firme identidad étnica y cultural que se traduce en una posición política, tal como ocurre con la poesía mapuche. El urgente llamado a preservar la tierra y los recursos que ella ofrece a los hombres se plasma en un 
programa de rescate de los valores tradicionales del pueblo mapuche y en una afirmación de la concepción nativa ligada a una toma de conciencia.

En este contexto, una tendencia poética que surge en Chile y que responde a la defensa del hábitat natural y de los recursos que ofrece la madre tierra a los pueblos nativos del continente es la poesía mapuche. En la tradición cultural mapuche, se enfatiza una actitud contestaria frente a la invasión de su espacio territorial y la exclusión a que son sometidos por el poder hegemónico y político en ese país. En este contexto, los poetas mapuches alzan una voz de protesta, buscan la afirmación de su identidad étnica y luchan para lograr reivindicaciones para su pueblo y cultura como objetivos mayores de su arte literario. Un sentimiento ecológico late en sus poesías, lo que se articula con un programa de valoración de la naturaleza y de rescate de la relación ancestral entre los hombres y la madre tierra.

De profunda raíz indígena, la poesía mapuche constituye una voz disímil que se contrapone al canon de la literatura chilena y cuestiona las representaciones elaboradas sobre la cultura nativa:

Los poetas mapuches irrumpen en la tradición del canon poético-literario chileno con una actitud transgresora, levantado y proponiendo una estética compleja, lo que produce contradicciones evidentes con las formas discursivas imperantes en el medio y con aquellas textualidades que tradicionalmente abordaron la temática indígena (Fierro y Geeragat, 2004, p. 78).

En Chile, la obra poética de Erwin Quintupil, Sebastián Queupul, Elicura Chihualaf, Leonel Lienlaf, Jiame Huenún y Bernardo Colipán, entre otros, demuestra la fuerza y la vitalidad de la poesía mapuche, que no solo posee honda capacidad expresiva y estética, sino que también se orienta al rescate de la relación ancestral del hombre con la naturaleza. En ese sentido, la poesía mapuche expresa "no solo denuncia sino también sueña e imagina que es posible recuperar los vínculos perdidos con la madre tierra que es la expresión de la reciprocidad de los hombres con la naturaleza en una actitud mágica y cósmica" (Fierro y Geeragat, 2004, p. 79).

Los versos del poema “Anciano" del poeta Erwin Quintupil abordan la relación existente entre el hombre y la naturaleza en la cosmovisión mapuche. En el poema, el medio natural es el lugar que acoge al personaje: "El campo está abierto / y al fondo la montaña que vigila / mojada y oscura / en que los escarabajos hurgan / llevando colores perdidos en su vagar" (1994, p. 87). Al llegar el anciano al campo, la naturaleza se manifiesta y el hombre escucha su voz: "E1 hombre, el anciano / se detuvo en algún punto del ciclo interminable / y habló el amarillo de la tierra cansada / la blandura del camino. / El bosque dijo su verde esperanza. / El aire detuvo su incesante caminar." (1994, p. 87). Los versos 
nos dicen que "todos hablaron por su voz" y entonces el hombre "buscó en su memoria relatos antiguos". En el poema, la relación dialógica entre el anciano y la naturaleza es vital para comprender la armonía espiritual que existe entre la vida humana, las plantas y la tierra.

El poeta mapuche es la voz autorizada que busca recuperar la memoria de la naturaleza, trata de expresar su sentimiento y de consustanciarse con los ríos, los lagos, las plantas, los árboles y darles voz. Esta identificación permite reencontrase con un territorio que necesita ser verbalizado y que reclama la intervención de los hombres. De esta manera, entendemos por qué los poetas mapuches viven una metamorfosis que los convierte en la expresión de la tierra: "escuchan los quejidos de la naturaleza herida y verbalizan su voz, su lamento o su esperanza, metamorfoseándose con ella, asumiéndose árboles, zorros, cóndores, lluvia, luna, peces, mar" (Fierro y Geeregat, p. 81).

Los versos del poema "Transformación" de Leonel Lienlaf nos transmiten esa necesidad de unión con los signos y elementos de la naturaleza, lo que se plasma mediante la asunción de la forma y espíritu del árbol: "La vida del árbol / invadió mi vida / comencé a sentirme árbol / y entendí su tristeza” (1989, p. 99). Esta metamorfosis pone de relieve el vínculo perdido que los hombres deben recobrar para volver a vivir ligados a la madre tierra. La voz lírica nos dice: "Empecé a llorar por mis hojas, / mis raíces, / mientras un ave / se dormía en mis ramas / esperando que el viento / dispersara sus alas. / Yo me sentía árbol / porque el árbol era mi vida" (1989, p. 99). Asumirse como árbol reafirma la comunión entre el hombre y el espíritu de la tierra, con lo que se consigue reestablecer el vínculo perdido que ahora ha logrado integrar la individualidad del ser con una nueva condición, que significa enraizarse en la naturaleza.

\section{Conclusiones}

La ecocrítica pone de manifiesto la problemática actual que enfrenta la naturaleza a raíz de la acción del hombre. Desde esa perspectiva, la literatura actúa como un gran mirador en la cual se puede observar el antropocentrismo con que el hombre ha actuado frente a la naturaleza y el poco espíritu de valoración de los medios de existencia que ella provee al ser humano. En una dirección contraria, una visión ecológica de la literatura afirma una concepción basada en el biocentrismo, que propone una nueva mirada de la naturaleza, así como un sentimiento de respeto y valoración. En esa línea, la literatura no puede desentenderse de un sentido ético que debe impulsar una actitud crítica en favor de la naturaleza y del verdadero sentido que tiene para el ser humano.

Las obras literarias ponen en evidencia las actitudes del hombre que han primado a través de la historia en relación con la naturaleza y también inciden en una mayor comprensión de los problemas y conflictos que la explotación 
humana y el aprovechamiento material han ocasionado a la tierra. Esta muestra el efecto de la acción del hombre, así como también plasma las posibilidades de valoración del hábitat natural. Arraigada en un sentimiento de defensa de la cultura nativa y de la memoria local, los pueblos nativos del continente buscan recuperar el legado de la tierra y de su valor ancestral, como se encarna en el proyecto programático del pueblo mapuche, cuya poesía representa un sentimiento de afirmación étnica y cultural frente al canon literario oficial.

\section{Referencias bibliográficas}

Barella, Vigal, J. (2010). “Naturaleza y paisaje en la literatura española”. En Flys Junquera, Carmen et al (2010).

Fierro, J. M. y Geeragat, O. (2004). "La memoria de la Madre Tierra: el canto ecológico de los poetas mapuches". Anales de la literatura hispanoamericana. Vol. 3, 2004, pp. 77-84.

Flores, W. (2015) Ecocritica poscolonial y literatura moderna latinoamericana. Lima: Fondo Editorial de la Universidad Nacional Mayor de San Marcos.

Flys Junquera, C. et al. Eds. (2010) Ecocriticas. Literatura y medio ambiente. Madrid: Iberoamericana.

Flys Junquera, C. et al (2010) "Ecocríticas: el lugar y la naturaleza como categorías de análisis literario". En Ecocríticas. Literatura y medio ambiente. Madrid: Iberoamericana.

Flys Junquera, C. (2010) “Literatura, crítica y justicia medioambiental”. En Ecocríticas. Literatura y medio ambiente. Madrid: Iberoamericana, pp.

Glotfelty, C. (2010) “Los estudios literarios en la era de la crisis medioambiental”. En Ecocriticas. Literatura y medio ambiente. Madrid: Iberoamericana, pp.

Heffes, G. (2014) Introducción. Para una ecocrítica latinoamericana: entre la postulación de un ecocentrismo crítico y la crítica a un antropocentrismo hegemónico. Revista de crítica literaria latinoamericana. Año, XI, N 79 , Lima-Boston, $1^{\mathrm{er}}$ semestre de 2014, pp. 11-34.

Lienlaf, L. (1989). Se ha despertado el ave de mi corazón. Santiago de Chile: Universitaria.

Marrero Henríquez,J.M. (2010) “Ecocrítica e hispanismo”. En Ecocríticas. Literatura $y$ medio ambiente. Madrid: Iberoamericana, pp.

-. (2014) Pertinencia de la ecocrítica. Revista de crítica literaria latinoamericana. Año, XI, N ${ }^{\circ} 79$, Lima-Boston, ${ }^{\text {er }}$ semestre de 2014, pp. 57-77.

Quintupil, E. (1994). Anciano. Pentukun, N 1, p. 87. 